\title{
The impact of ethnic density on dispensing of antipsychotic and antidepressant medication among immigrants in the Netherlands
}

Citation for published version (APA):

Termorshuizen, F., Heerdink, E. R., \& Selten, J-P. (2018). The impact of ethnic density on dispensing of antipsychotic and antidepressant medication among immigrants in the Netherlands. Social Science \& Medicine, 211, 87-94. https://doi.org/10.1016/j.socscimed.2018.06.005

Document status and date:

Published: 01/08/2018

DOI:

10.1016/j.socscimed.2018.06.005

Document Version:

Publisher's PDF, also known as Version of record

Document license:

Taverne

Please check the document version of this publication:

- A submitted manuscript is the version of the article upon submission and before peer-review. There can be important differences between the submitted version and the official published version of record.

People interested in the research are advised to contact the author for the final version of the publication, or visit the DOI to the publisher's website.

- The final author version and the galley proof are versions of the publication after peer review.

- The final published version features the final layout of the paper including the volume, issue and page numbers.

Link to publication

\footnotetext{
General rights rights.

- You may freely distribute the URL identifying the publication in the public portal. please follow below link for the End User Agreement:

www.umlib.nl/taverne-license

Take down policy

If you believe that this document breaches copyright please contact us at:

repository@maastrichtuniversity.nl

providing details and we will investigate your claim.
}

Copyright and moral rights for the publications made accessible in the public portal are retained by the authors and/or other copyright owners and it is a condition of accessing publications that users recognise and abide by the legal requirements associated with these

- Users may download and print one copy of any publication from the public portal for the purpose of private study or research.

- You may not further distribute the material or use it for any profit-making activity or commercial gain

If the publication is distributed under the terms of Article 25fa of the Dutch Copyright Act, indicated by the "Taverne" license above, 


\title{
The impact of ethnic density on dispensing of antipsychotic and antidepressant medication among immigrants in the Netherlands
}

\author{
Fabian Termorshuizen $^{\mathrm{a}, \mathrm{b}, *}$, Eibert R. Heerdink ${ }^{\mathrm{b}, \mathrm{c}}$, Jean-Paul Selten ${ }^{\mathrm{a}, \mathrm{d}}$

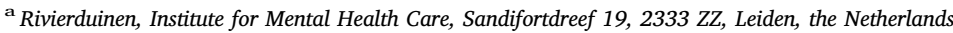 \\ ${ }^{\mathrm{b}}$ Division of Pharmacoepidemiology and Clinical Pharmacology, Utrecht Institute for Pharmaceutical Sciences, Utrecht University, P.O. Box 80082, 3508 TB, Utrecht, the \\ Netherlands \\ ${ }^{\mathrm{c}}$ Department of Clinical Pharmacy, University Medical Center Utrecht, Heidelberglaan 100, 3584 CX, Utrecht, the Netherlands \\ ${ }^{\mathrm{d}}$ Department of Psychiatry and Psychology, School for Mental Health and Neuroscience MHeNS, Maastricht University, Universiteitssingel 40, 6229 ER, Maastricht, the \\ Netherlands
}

\section{A R T I C L E I N F O}

\section{Keywords:}

Ethnic minorities

Ethnic density

Pharmaco-epidemiology

Antipsychotics

Antidepressants

\begin{abstract}
A B S T R A C T
Purpose: A higher own-group ethnic density in the area of residence is often associated with a lower risk for psychotic disorder. For common mental disorders the evidence is less convincing. This study explores whether these findings are mirrored in data on dispensing of antipsychotics and antidepressants.

Methods: Health insurance data on dispensed medication among all adults living in the four largest Dutch cities were linked to demographic data from Statistics Netherlands. Dispensing of antipsychotics and antidepressants in 2013 was analyzed in relation to the proportion of the own ethnic group in the neighborhood.

Results: Higher own-group ethnic density was associated with lower dispensing of antipsychotics among the Moroccan-Dutch $(\mathrm{N}=115,455)$, after adjusting for age, gender, and SES of the neighborhood $\left(\mathrm{OR}_{\mathrm{adj}}\right.$ for the highest vs. the lowest density quintile $=0.72[0.66-0.79]$ ). However, this association vanished after adjustment for household composition $\left(\mathrm{OR}_{\mathrm{adj}}=0.93\right.$ [0.85-1.03]). Similar results were found for the Turkish-Dutch $(\mathrm{N}=105,460)\left(\mathrm{OR}_{\mathrm{adj}}=0.86[0.76-0.96]\right.$ and $\left.1.05[0.94-1.18]\right)$. For those of Surinamese $(\mathrm{N}=147,123)$ and Antillean origin $(\mathrm{N}=41,430)$, in contrast, the association between ethnic density and lower risk remained after each adjustment $(\mathrm{P}<0.001)$. For antidepressants, a negative association with own-group ethnic density was consistently found for those of Antillean origin $\left(\mathrm{OR}_{\mathrm{adj}}=0.62[0.52-0.74]\right)$ only.

Conclusion: These data on dispensing of psychomedication confirm the ethnic density hypothesis for psychosis alongside earlier equivocal findings for other mental disorders. The negative association between own-group ethnic density and dispensing of antipsychotics among the Moroccan- and Turkish-Dutch may be explained, at least in part, by a favourable household composition (i.e., living in a family) in high-density neighborhoods.
\end{abstract}

\section{Introduction}

There are consistent reports in the literature of an increased incidence of psychotic disorder among certain ethnic minorities in Western Europe (Cantor-Graae and Selten, 2005; Bourque et al., 2011). There is converging evidence for a role of social factors in the host country such as discrimination and social exclusion in its etiology. No increased prevalence of psychotic disorder in the country of origin was found and selective migration and/or diagnostic bias due to cultural misinterpretation do not explain this higher risk conclusively (Bhugra et al., 1996; Fearon and Morgan, 2006; Selten et al., 2010; van der Ven et al., 2015; Zandi et al., 2010). One of the arguments for a role of social factors is the ethnic density effect: a lower risk of psychotic disorder among members of ethnic minorities who live in areas with many individuals of their own ethnic group (Bosqui et al., 2014; Shaw et al., 2012). Moving to neighborhoods with a lower ethnic minority density as a result of the (emerging) psychosis ('social drift') appears to be an unlikely explanation, as low minority ethnic density areas are often the more affluent neighborhoods (Schofield et al., 2017; Termorshuizen et al., 2014).

For common mental disorders such as depression, however, the evidence of a higher risk associated with ethnic minority status (Mindlis and Boffetta, 2017) and of a favourable influence of the presence of the own ethnic group in the area of residence is less consistent (Shaw et al., 2012; Schrier et al., 2014; Tarricone et al., 2012). The outcome of investigations varied according to the type of recruitment (field survey or

\footnotetext{
* Corresponding author. Institute for Mental Health Care, Sandifortdreef 19, 2333 ZZ, Leiden, the Netherlands.

E-mail address: f.termorshuizen@rivierduinen.nl (F. Termorshuizen).
} 
treatment-based) and the ethnic group under study. Furthermore, the use of small samples, differences in referral patterns to specialist care, and/or investigations of too broad area levels may obscure important effects (Shaw et al., 2012; Schofield et al., 2016a).

A recent study of a large database of health records of General Practitioners (GP) that covered four ethnically diverse districts in London reported a much lower risk of new depression diagnoses among ethnic minorities and a favourable effect of ethnic density of the neighborhood in general (Schofield et al., 2016a). There were differences between ethnic groups, with a favourable ethnic density effect among those of Pakistani, Indian, Bangladeshi, and African orgin (ORs $<1.00$ ), but with a reversed association (more new depression diagnoses in higher own-group dense neighborhoods, OR $>1.00$ ) among those of Caribbean origin. As for this group, a favourable influence of ethnic density in the neighborhood of residence may have been overruled by more disadvantaged living conditions for which the statistical adjustments may not have been sufficient. Important for the present study, the latter study showed similar results when prescriptions of antidepressants were used as outcome (instead of registered diagnosis). This was in agreement with earlier methodologically weak studies that explored ethnic density effects on the practice level, but not as an interaction effect between individual ethnicity and neighborhood ethnic density (Hull et al., 2001; Morrison et al., 2009; Walters et al., 2008). A recent survey in South East London reported that a lower owngroup proportion in the residential area was associated with more psychotic experiences, but not with depression among Black persons of African or Caribbean origin, thus confirming the absence of a favourable ethnic density effect for depressive disorders described above for Black persons of Caribbean origin (Schofield et al., 2016b). A few other survey studies found ethnic density effects for common mental disorders, eg among Indians and Caribbeans (Halpern and Nazroo, 2000), among Blacks (Becares et al., 2014; Yuan, 2008), and among Bangladeshi and Irish persons (Das-Munshi et al., 2010). Other survey studies failed to find density effects for depression among Hispanics (Yuan, 2008), and for a broadly defined measure of psychological wellbeing (Shields and Wailoo, 2002). In the British Household Panel Survey in the UK, no interaction between being non-White and ethnicity of the neighborhood for the basic core of psychiatric symptoms measured with the General Health Questionnaire was found (Propper et al., 2005). A number of cohort studies in the US contribute to the mixed evidence for ethnic density effects on the risk for depressive disorder (Henderson et al., 2005; Mair et al., 2010). In summary, there is a lot of heterogeneity of research findings concerning ethnic density effects on mental disorders other than psychosis. This was also found in a recent meta-analysis with a summary of recent literature on ethnic density effects for various mental health outcomes (Becares et al., 2017).

The present record-linkage study analyzed data on both dispensed antipsychotic and dispensed antidepressant medication in relation to the own-group ethnic density in the neighborhood of residence for several ethnic minorities in the four largest cities in the Netherlands. This was done as these two different outcomes associated with two different mental disorders (severe vs more common) could be analyzed with data derived from the same population and with identical analytic methods. We regarded dispensed medication as proxy for the presence of diagnosed and treated mental disorders at the population level. Albeit there are important limitations in using data on dispensed medication as outcome, these data may be useful when interpreted in connection with well-designed studies with data on the associated disorders itself.

This study is a continuation of an earlier analysis of the same database (Termorshuizen et al., 2017), which showed much higher use of antipsychotic and antidepressant medication among the Moroccan- and Turkish-Dutch than among the native Dutch, but similar and even lower use of several classes of psychomedication among those of Surinamese and Antillean origin. Remarkably, for those of Moroccan and Turkish origin, but not for those of Surinamese and Antillean origin, adjustment for household composition resulted in higher relative risk estimates. This suggested a favourable influence of membership of a household with a co-habiting or married couple on the use of psychotropic medication. This raises the question as to whether this may be a correlate of ethnic density effects for certain minority groups (Termorshuizen et al., 2014; Veling et al., 2008). A higher minority ethnic density of the neighborhood is in general associated with worse socio-economic circumstances. As a lower socio-economic status (SES) is associated - either as cause or effect or both-with a higher risk of psychiatric disorder, a favourable ethnic density effect in an ethnic minority group is operational in the opposite direction of the unfavourable effect of SES and, for this reason, a little counter-intuitive (Denton et al., 2015). Thus, a favourable association with ethnic density, if observed, may indicate a strong favourable effect of ethnic density for that minority group, and the association may appear stronger after adjustment for SES. Also, absence of an association with ethnic density in a certain ethnic minority group may suggest the presence of a favourable effect of ethnic density, that may come to light after adjustment for SES. The present study examined whether own-group ethnic density in the neighborhood influences the dispensing rates of antipsychotic and antidepressive medication and analyzed the impact of adjustments for SES and for household composition.

\section{Methods}

\subsection{Datasources}

Two data-sources were used. First, the population register (Dutch: Gemeentelijke Basis Administratie, GBA) of Statistics Netherlands (Dutch: Centraal Bureau voor de Statistiek, CBS), which records information on basic demographic data for all legally residing citizens of The Netherlands.

The second database, from the Health Care Institute Netherlands (Dutch: Zorginstituut Nederland, ZiN), contains information on prescribed and dispensed medication reimbursed by health-insurance companies during the period 2006-2013. The data have been derived from all health-insurance companies in The Netherlands and have been collected for the purpose of risk adjustments, because some companies insure more patients with a high risk of expensive health care utilization than others. Dutch citizens are obliged by law to have a medical insurance. Since there is no distinction between public and private health insurance companies, the results of our study are not influenced by selection of immigrants who can afford a health insurance. This database records information on drugs dispensed to outpatients and patients in nursing homes, not on drugs dispensed during episodes of inpatient treatment.

The medication is dispensed by the pharmacist, only if there is a prescription from the responsible physician. In the presence of a prescription, the medication is reimbursed by the health insurance company, and registerered in the database from which the files for our analysis were extracted.

For a particular calendar year and for a given individual, the first four positions of the code(s) of the medication(s) according to the Anatomical Therapeutic Chemical Classification System (ATC code) are registered. Dispensed medications within a calendar year with identical first four positions are mentioned only once for that subject. Thus, it is possible to establish whether a person had medication dispensed within a certain calendar year and for which broad class (es) of drugs (e.g., N06A, antidepressants; A10A, insulins and analogues).

Staff of CBS linked the information from the two databases, using the civil identification number, unique for each Dutch citizen. Dutch privacy laws allow the use of personal (health care) data for medicalscientific research without informed consent, provided that the results of the analysis cannot be traced to a unique person (Hooghiemstra, 2002). 


\subsection{Data extraction}

In order to prevent the occurrence of correlated data within the same individual, the present analysis was restricted to one calendar year (2013). The analysis was also restricted to those aged 18 years and older and to persons resident during (a part of) this year in one of the four large cities in The Netherlands (Amsterdam, Rotterdam, The Hague, Utrecht). Most members of ethnic minorities in The Netherlands live in these cities, and this restriction made adjustments for population density or for urban-rural differences superfluous. Data on dispensed antipsychotic (ATC code N05A, including N05AN01, Lithium) and antidepressant medication (N06A) was analyzed, leaving other medication out of consideration. Characteristics of the household (i.e., being part of a family with a married or cohabiting couple, part of a oneparent family, being single or living in an institute), as established at January 1st' 2013, were regarded as time-independent during 2013. SES was established at the neighborhood level and defined as the proportion of households that were dependent on the social welfare system (in Dutch: de Bijstand) due to unemployment. If a person moved to another neighborhood in the same or another city during 2013, an average of this proportion for that person was calculated (see below for ethnic density).

\subsection{Definition of ethnic origin and density}

The CBS classifies origin according to a citizen's country of birth and the country of his or her parents' birth. A Dutch-born subject with two Dutch-born parents is considered native Dutch. If a citizen has been born abroad, he or she is assigned to the ethnic origin of the people born in the same country, that is, ethnic origin was not defined on the basis of self-identified ethnicity. This person is regarded as a first-generation immigrant. The data do not allow a distinction between ethnic groups within a country of origin, especially for those from Surinam (Blacks and Asians). A Dutch-born citizen is considered a second-generation immigrant if at least one of his/her parents was foreign-born. If the parents were born in different foreign countries, the maternal country of birth was decisive for assignment to a particular group. Since most non-Western minorities in The Netherlands originate from Turkey, Morocco, Surinam and the Netherlands Antilles, the analysis was restricted to these groups. Both first and second-generation immigrants were included according to the definition of ethnic minority group used by the CBS.

Within each neighborhood, the proportion of persons belonging to a particular ethnic minority group in 2013 was calculated and was regarded as measure of ethnic density associated with that ethnic group. We used the official codes of the CBS for delineation of neighborhoods, which are defined by postal codes and in accordance with municipal regulations.

If an individual person of that ethnic minority group did not move from one neighborhood to another in 2013, this measure was also regarded as the indvidual exposure to the own-group ethnic density in 2013. If a person did move within 2013, an average exposure to the own-group ethnic density associated with the subsequent neighborhoods of residence was calculated, weighted for the duration of episodes living in these neighborhoods within 2013. The exposure to Moroccan, Turkish, Surinam and Antillean density of the neighborhood of residence in 2013 was also calculated for each native Dutch person. The exposure to the own-group ethnic density was categorized in quintiles.

\subsection{Analysis}

For each minority group, a multivariable logistic regression model was used to establish the association between the own-group ethnic density within the neighborhood of residence (categorized in quintiles) and the prevalence of dispensed antipsychotic medication (Table 2).
Native Dutch persons were included as a comparison group and their prevalence of dispensed antipsychotic medication was analyzed according to the same quintiles for ethnic density of the minority group of interest. Among native Dutch, the effect of lower SES and the effect of higher minority ethnic density (ie, lower White density) are operational in the same direction. Thus, the association with minority ethnic density among the native Dutch may be regarded as 'standard', as the 'expected association to compare with', as this association is what you also can expect for the various migrant groups if no favourable effect of own-group ethnic density was operational. Inclusion of four terms for interaction of "ethnic group (ie, minority vs native Dutch) $\mathrm{x}$ minority ethnic density" in the model made it possible to estimate separate effects of minority ethnic density for those belonging to the ethnic minoity group and for native Dutch persons, and to test the statistical significance of this interaction. In the first step (I.), the model was adjusted for age ( $\geq 18-30,30-40,40-60$, and $\geq 60$ years) and gender. In the second step (II.), this model was adjusted for age, gender, and neighborhood SES, and in the third step (III.), this model was adjusted for age, gender, SES and household composition. The proportion of households dependent on the social welfare system in a neighborhood was categorized in quintiles with the lowest quintile $(<25 / 1000$ households) as reference. In these models, the lowest quintile for ethnic density was the reference category, and, thus, a negative association between a higher ethnic density and a lower dispensing of medication will appear as an $\mathrm{OR}<1$. The same analysis was done for dispensing of antidepressants (Table 3). To exclude a diagnosis of dementia as reason for dispensing antipsychotics, analyses were also done separately for young persons ( $<40$ years). Furthermore, earlier studies showed high relative risks of psychosis (Selten et al., 2001; Veling et al., 2006) and of dispensed antipsychotics (Termorshuizen et al., 2017) among Moroccan males aged $<40$ years. For antidepressants, high relative risks of dispensing were found among Moroccan females aged $<40$ and males aged $\geq 40$ years (Termorshuizen et al., 2017). To find out whether ethnic density density effects were more pronounced among those with the highest risks of certain mental disorders and associated psychomedication, both analyses for antipsychotics and antidepressants were done separately for strata defined by age $(<40$ vs $\geq 40)$ and gender (Appendix, Supplementary Tables 2.1-2.4, Supplementary Tables 3.13.4).

In a sensitivity analysis, the models were re-run with random effects for neighborhood (random intercept and random slope for ethnic group). This was done to find out whether ignoring the correlation due to clustering of data within neighborhoods may have resulted in biased estimates in the main analysis. This sensitivity analysis was restricted to persons who did not change their residence in 2013, as the information on dispensed medication for an individual person was related to a calendar year as a whole and could not be assigned to an episode of residence in a specific neighborhood when moving from one neighborhood to another within that year. In such multilevel model with random effects for neighborhood, the correlation between data on dispensing of medication of individuals living in the same neighborhood (in 2013) was taken into account. This presupposes that the data on use can be assigned one-to-one to a certain neigborhood and this necessarily excludes those residing in two (or more) neighborhoods within 2013.

Due to small to zero numbers of persons from ethnic minority groups in high own-group minority dense neighborhoods in the higher SES categories, the neighborhood SES was dichotomized in this analysis in proportion of households dependent on social welfare $\geq 138 / 1000$ (lowest SES) vs. < 138/1000 (higher SES), in stead of categorizing in quintiles. This was done to make convergence of the models possible.

Data management and record linkage were performed with SPSS version 21.0. The logistic regression analyses were performed with STATA, version 14.0. The multilevel analysis was done with STATA procedure GLAMM (Rabe-Hesketh, 2005). 
Table 1

A Characteristics of the native Dutch and the four ethnic minority groups, and for the minorities by own-group ethnic minority density of the neighborhood of residence, 2013.

\begin{tabular}{|c|c|c|c|c|c|c|c|}
\hline & \multirow[t]{2}{*}{$\%<40$ year } & \multirow[t]{2}{*}{$\%$ Male } & \multirow{2}{*}{$\begin{array}{l}\text { Low SES of the neighborhood } \\
\% \geq 138 / 1000 \text { households }\end{array}$} & \multicolumn{4}{|c|}{ Household characteristics } \\
\hline & & & & $\begin{array}{l}\text { 1. Married/ } \\
\text { cohabiting }\end{array}$ & 2.Single parent & 3. Unmarried & $\begin{array}{l}\text { 4. Other/ } \\
\text { unknown }\end{array}$ \\
\hline Native Dutch $(\mathrm{N}=1,043,732)$ & $41.2 \%$ & $48.5 \%$ & $14.1 \%$ & $55.7 \%$ & $5.8 \%$ & $34.5 \%$ & $3.7 \%$ \\
\hline Turkish $(\mathrm{N}=105,460)$ by density $(\%)$ & $57.4 \%$ & $52.0 \%$ & $50.6 \%$ & $70.2 \%$ & $10.2 \%$ & $15.3 \%$ & $4.0 \%$ \\
\hline $1 .<4.9$ & $58.2 \%$ & $52.3 \%$ & $10.8 \%$ & $63.7 \%$ & $10.7 \%$ & $19.8 \%$ & $5.8 \%$ \\
\hline 2. $4.9-9.4$ & $56.7 \%$ & $51.9 \%$ & $32.4 \%$ & $69.8 \%$ & $10.4 \%$ & $15.5 \%$ & $4.3 \%$ \\
\hline 3. $9.4-14.0$ & $57.6 \%$ & $52.2 \%$ & $50.0 \%$ & $71.5 \%$ & $10.2 \%$ & $14.8 \%$ & $3.5 \%$ \\
\hline 4. $14.0-22.5$ & $59.4 \%$ & $52.5 \%$ & $73.6 \%$ & $71.9 \%$ & $9.7 \%$ & $14.5 \%$ & $3.8 \%$ \\
\hline 5. $>22.5$ & $55.2 \%$ & $51.4 \%$ & $83.3 \%$ & $73.7 \%$ & $10.3 \%$ & $12.6 \%$ & $3.5 \%$ \\
\hline Moroccan $(\mathrm{N}=115,455)$ by density $(\%)$ & $57.5 \%$ & $51.8 \%$ & $46.4 \%$ & $67.0 \%$ & $9.8 \%$ & $16.2 \%$ & $6.7 \%$ \\
\hline 1. $<5.7$ & $61.9 \%$ & $52.2 \%$ & $8.0 \%$ & $60.3 \%$ & $11.0 \%$ & $20.0 \%$ & $8.7 \%$ \\
\hline 2. $5.7-10.7$ & $59.4 \%$ & $52.9 \%$ & $24.3 \%$ & $64.1 \%$ & $10.1 \%$ & $17.5 \%$ & $8.2 \%$ \\
\hline 3. $10.7-15.8$ & $57.3 \%$ & $52.2 \%$ & $61.9 \%$ & $65.9 \%$ & $9.8 \%$ & $17.0 \%$ & $7.3 \%$ \\
\hline 4. $15.8-22.1$ & $54.1 \%$ & $50.9 \%$ & $59.8 \%$ & $70.3 \%$ & $9.7 \%$ & $14.2 \%$ & $5.8 \%$ \\
\hline 5. $>22.1$ & $55.7 \%$ & $51.2 \%$ & $68.6 \%$ & $73.4 \%$ & $8.9 \%$ & $13.1 \%$ & $4.6 \%$ \\
\hline Surinamese $(\mathrm{N}=147,123)$ by density $(\%)$ & $44.8 \%$ & $46.4 \%$ & $43.8 \%$ & $43.0 \%$ & $22.8 \%$ & $29.0 \%$ & $4.9 \%$ \\
\hline 1. $<5.5$ & $45.4 \%$ & $47.5 \%$ & $5.4 \%$ & $41.7 \%$ & $18.3 \%$ & $33.9 \%$ & $6.1 \%$ \\
\hline 2. $5.5-8.9$ & $44.8 \%$ & $45.9 \%$ & $20.0 \%$ & $40.5 \%$ & $24.1 \%$ & $30.3 \%$ & $5.2 \%$ \\
\hline 3. $8.9-11.8$ & $45.2 \%$ & $46.8 \%$ & $60.4 \%$ & $41.1 \%$ & $24.2 \%$ & $30.0 \%$ & $4.7 \%$ \\
\hline 4. $11.8-18.9$ & $45.4 \%$ & $47.1 \%$ & $39.9 \%$ & $49.5 \%$ & $20.8 \%$ & $25.0 \%$ & $4.7 \%$ \\
\hline 5. $>18.9$ & $43.2 \%$ & $45.0 \%$ & $90.2 \%$ & $42.7 \%$ & $26.3 \%$ & $26.3 \%$ & $4.7 \%$ \\
\hline $\begin{array}{l}\text { Neth. Antillean }(\mathrm{N}=41,430) \text { by density } \\
\quad(\%)\end{array}$ & $61.2 \%$ & $48.9 \%$ & $40.1 \%$ & $34.0 \%$ & $20.6 \%$ & $36.5 \%$ & $8.6 \%$ \\
\hline 1. $<1.1$ & $57.0 \%$ & $50.3 \%$ & $10.7 \%$ & $41.8 \%$ & $12.1 \%$ & $39.5 \%$ & $6.5 \%$ \\
\hline 2. $1.1-2.3$ & $59.3 \%$ & $49.6 \%$ & $11.6 \%$ & $37.1 \%$ & $17.8 \%$ & $35.7 \%$ & $9.4 \%$ \\
\hline 3. $2.3-4.0$ & $64.1 \%$ & $49.9 \%$ & $47.9 \%$ & $31.8 \%$ & $20.0 \%$ & $37.9 \%$ & $10.2 \%$ \\
\hline 4. $4.0-5.9$ & $61.4 \%$ & $48.3 \%$ & $51.7 \%$ & $32.9 \%$ & $24.9 \%$ & $33.3 \%$ & $9.0 \%$ \\
\hline 5. $>5.9$ & $63.1 \%$ & $47.2 \%$ & $69.2 \%$ & $28.4 \%$ & $26.1 \%$ & $37.4 \%$ & $8.1 \%$ \\
\hline
\end{tabular}

a Defined as at least 138 per 1000 households in a neighborhood (highest quintile) that are dependent on the social welfare system.

\section{Results}

\subsection{Description and differences by ethnic density}

Table 1A shows the numbers and characteristics of the included subjects, by ethnic group, and, for the ethnic minorities, the distribution of these characteristics by quintiles for own-group ethnic density. There were major differences between the ethnic groups in age distribution, SES of the neighborhood of residence and household composition, and between the quintiles for ethnic density in neighborhood SES, with the highest proportions of households dependent on the social welfare system in neighborhoods with the highest minority ethnic density. Among the Turkish- and Moroccan-Dutch, the proportion of persons who are part of a household with a married or cohabiting couple increased with increasing own-group ethnic density. Among the Surinamese- and Antillean-Dutch, in contrast, the proportion of persons who are part of a one-parent family increased with increasing owngroup ethnic density. Crude figures on dispensing of antipsychotic and antidepressant medication are shown in Supplementary Table 1.B.

\subsection{Antipsychotics: multivariable logistic regression}

Table 2 shows the results of the multivariable models on the dispensing of antipsychotic medication. Among the native Dutch, there was a clear trend towards higher ORs of dispensing of antipsychotic medication with increasing ethnic minority density for each combination with a particular minority group. These associations decreased in strength, disappeared or became even reversed (eg, for native Dutch in neighborhoods with many Surinamese-Dutch individuals) after adjustment for neighborhood SES (included as variable categorized in quintiles).

With reference to the Turkish- and Moroccan-Dutch (see also Supplementary Fig. 1), after adjustment for neighborhood SES (categorized in quintiles), a higher own-group ethnic density appeared to be significantly associated with lower dispensing of antipsychotic medication $(\mathrm{P}=0.0122$ and $\mathrm{P}<0.0001$, respectively). These negative ('favourable') associations with own-group ethnic density differred significantly from the corresponding positive ('unfavourable') associations within the native Dutch population, as evidenced by statistically significantly terms for the 1st-order interaction of \{(ethnic minority vs. native Dutch) $\mathrm{x}$ ethnic minority density $\}$ ( $\mathrm{P}$ values $<0.001)$.

Interestingly, however, these negative associations in support of the ethnic density hypothesis, disappeared after further adjustment for household composition. Among the Turkish-Dutch, the ORs became all higher than 1.00. Among the Moroccan-Dutch, the OR associated with the highest quintile for ethnic density increased from 0.72 [0.66-0.79] to 0.93 [0.85-1.03], and the terms for the interaction were no longer statistically significant $(\mathrm{P}=0.3157)$.

Among the Surinamese- and Antillean-Dutch, in contrast, the ORs of dispensing of antipsychotic medication among those in the higher quintiles compared to those in the lowest quintile for the own-group ethnic density remained consistently lower than 1.00 , with statistically significant terms for the interaction, irrespective of what adjustment was applied.

\subsection{Antipsychotics: multivariable logistic regression by age and gender}

Supplementary Tables 2.1-2.4 show the results of the same analysis, but for separate age-gender strata. In general, the ORs associated with higher own-group minority density in the separate age-gender strata followed the pattern found for the different ethnic groups as a whole (Table 2), but the statistical significance was sometimes less pronounced or was lost. A pronounced and favourable effect of minority density was found among Moroccan males aged $<40$ years, after adjustment for SES (categorized in quintiles) (Suppl. Table 2.1), but also among Moroccan females aged $\geq 40$ years (Suppl. Table 2.4). 
Table 2

Use of antipsychotics with increasing ethnic minority density of the neighborhood, by ethnic group.

\begin{tabular}{|c|c|c|c|c|c|c|}
\hline \multirow[t]{2}{*}{ ORs [95\%-CI], adjusted for: } & \multicolumn{3}{|c|}{ Within native Dutch } & \multicolumn{3}{|c|}{ Within ethnic minority associated with the density quintiles shown } \\
\hline & Age \& Gender & “ \& neighb. SES & “ \& household c. & Age \& Gender & “\& neighb. SES & “ \& household c. \\
\hline \multicolumn{7}{|l|}{ Turkish density (\%) } \\
\hline 1. $<4.9$ & 1.00 & 1.00 & 1.00 & 1.00 & 1.00 & 1.00 \\
\hline 2. 4.9-9.4 & $1.28[1.23-1.33]$ & 1.05 [1.01-1.09] & $1.04[1.00-1.08]$ & $1.17[1.05-1.30]$ & $1.01[0.91-1.13]$ & $1.15[1.03-1.28]$ \\
\hline 3. $9.4-14.0$ & $1.45[1.39-1.52]$ & $1.09[1.04-1.15]$ & $1.04[0.99-1.09]$ & $1.23[1.10-1.36]$ & $0.98[0.88-1.09]$ & $1.16[1.04-1.29]$ \\
\hline 4. $14.0-22.5$ & $1.46[1.37-1.56]$ & $1.07[1.00-1.15]$ & $1.02[0.95-1.09]$ & $1.20[1.08-1.34]$ & $0.93[0.84-1.04]$ & $1.10[0.98-1.23]$ \\
\hline 5. $>22.5$ & $1.86[1.70-2.04]$ & $1.33[1.20-1.46]$ & 1.24 [1.13-1.37] & $1.13[1.01-1.26]$ & $0.86[0.76-0.96]$ & 1.05 [0.94-1.18] \\
\hline$P$ value: within $^{\mathrm{a}} /$ interaction $^{\mathrm{b}}$ & $<0.001^{\mathrm{a}}$ & $<0.001^{\mathrm{a}}$ & $<0.001^{\mathrm{a}}$ & $<0.001^{\mathrm{a}} /<0.001^{\mathrm{b}}$ & $0.0122^{\mathrm{a}} /<0.001^{\mathrm{b}}$ & $0.0375^{\mathrm{a}} / 0.001^{\mathrm{b}}$ \\
\hline \multicolumn{7}{|l|}{ Moroccan density (\%) } \\
\hline 1. $<5.7$ & 1.00 & 1.00 & 1.00 & 1.00 & 1.00 & 1.00 \\
\hline 2. $5.7-10.7$ & $1.30[1.26-1.35]$ & $1.06[1.02-1.10]$ & $1.02[0.98-1.06]$ & $1.03[0.94-1.13]$ & $0.90[0.82-0.99]$ & 0.99 [0.90-1.09] \\
\hline 3. $10.7-15.8$ & $1.45[1.39-1.52]$ & $1.10[1.04-1.15]$ & $1.05[1.00-1.10]$ & $1.10[1.01-1.20]$ & $0.89[0.81-0.97]$ & $1.05[0.96-1.15]$ \\
\hline 4. $15.8-22.1$ & $1.35[1.27-1.43]$ & $0.99[0.93-1.05]$ & $0.94[0.88-1.00]$ & $0.96[0.88-1.06]$ & $0.76[0.69-0.83]$ & $0.96[0.87-1.05]$ \\
\hline $5 .>22.1$ & $1.64[1.54-1.76]$ & $1.17[1.09-1.26]$ & $1.04[0.96-1.12]$ & $0.93[0.85-1.02]$ & $0.72[0.66-0.79]$ & $0.93[0.85-1.03]$ \\
\hline$P$ value: within $^{\mathrm{a}} /$ interaction $^{\mathrm{b}}$ & $<0.001$ & $<0.001$ & 0.0282 & $0.0011 /<0.001$ & $<0.001 /<0.001$ & $0.0777 / 0.3157$ \\
\hline \multicolumn{7}{|l|}{ Surinamese density (\%) } \\
\hline 1. $<5.5$ & 1.00 & 1.00 & 1.00 & 1.00 & 1.00 & 1.00 \\
\hline 2. $5.5-8,9$ & 1.15 [1.11-1.18] & $0.88[0.84-0.91]$ & $0.93[0.90-0.97]$ & $0.92[0.83-1.01]$ & $0.74[0.67-0.82]$ & $0.84[0.76-0.92]$ \\
\hline 3. $8.9-11.8$ & $1.32[1.27-1.37]$ & $0.90[0.86-0.95]$ & $0.99[0.94-1.04]$ & $0.97[0.88-1.07]$ & $0.71[0.64-0.78]$ & $0.86[0.78-0.95]$ \\
\hline 4. $11.8-18.9$ & $1.30[1.24-1.37]$ & $0.97[0.92-1.03]$ & $1.06[1.01-1.12]$ & $0.89[0.81-0.98]$ & $0.68[0.62-0.76]$ & $0.85[0.77-0.95]$ \\
\hline 5. $>18.9$ & $1.29[1.19-1.40]$ & $0.78[0.71-0.85]$ & $0.88[0.80-0.96]$ & $0.77[0.70-0.86]$ & $0.50[0.45-0.56]$ & $0.64[0.58-0.72]$ \\
\hline $\mathrm{P}$ value: within $^{\mathrm{a}} /$ interaction $^{\mathrm{b}}$ & $<0.001$ & $<0.001$ & $<0.001$ & $<0.001 /<0.001$ & $<0.001 /<0.001$ & $<0.001 /<0.001$ \\
\hline \multicolumn{7}{|l|}{ Antillean density (\%) } \\
\hline $1 .<1.1$ & 1.00 & 1.00 & 1.00 & 1.00 & 1.00 & 1.00 \\
\hline 2. $1.1-2.3$ & $1.19[1.16-1.23]$ & $1.06[1.02-1.10]$ & $1.08[1.05-1.12]$ & $0.99[0.81-1.21]$ & $0.91[0.75-1.11]$ & $0.90[0.73-1.10]$ \\
\hline 3. $2.3-4.0$ & $1.38[1.32-1.44]$ & $1.07[1.02-1.12]$ & $1.07[1.02-1.12]$ & $0.91[0.74-1.11]$ & $0.71[0.58-0.87]$ & $0.73[0.60-0.89]$ \\
\hline 4. $4.0-5.9$ & $1.50[1.43-1.56]$ & $1.10[1.05-1.16]$ & 1.13 [1.08-1.19] & $0.78[0.64-0.95]$ & $0.60[0.49-0.73]$ & $0.64[0.53-0.79]$ \\
\hline 5. $>5.9$ & $1.54[1.45-1.64]$ & $1.06[0.99-1.13]$ & $1.11[1.03-1.19]$ & $0.63[0.51-0.79]$ & $0.46[0.37-0.58]$ & $0.49[0.39-0.62]$ \\
\hline$P$ value: within $^{\mathrm{a}} /$ interaction $^{\mathrm{b}}$ & $<0.001$ & $<0.001$ & $<0.001$ & $<0.001 /<0.001$ & $<0.001 /<0.001$ & $<0.001 /<0.001$ \\
\hline
\end{tabular}

a within: differences between ORs within a group $(\mathrm{df}=4)$.

b interaction: 1st-order interaction of $\{($ ethnic minority vs. native Dutch $) \mathrm{x}$ ethnic density $\}(\mathrm{df}=4)$.

\subsection{Antipsychotics: multivariable logistic regression with multilevel modelling}

The analysis restricted to those without residential move in 2013 and in which the within-neighborhood clustering was taken into account showed similar results for the Surinamese- $(\mathrm{N}=125,639)$ and Antillean-Dutch $(\mathrm{N}=30,164)$. However, the negative association with own-group density was not present among the Turkish- $(\mathrm{N}=90,391)$ or Moroccan-Dutch $(\mathrm{N}=98,870)$. In comparison with the increasing ORs with increasing minority density among the native Dutch, there was a strong indication for a relative density effect, that is, there was no such consistent increase in ORs among the Turkish- and the MoroccanDutch. The terms for the $1^{\text {st }}$-order interactions were highly significant ( $\mathrm{P}$ values $<0.001)$. Among the Moroccan-Dutch, this interaction disappeared after adjustment for household composition $(\mathrm{P}=0.5116)$, whereas the interaction among the Turkish-Dutch was still present $(P<0.001)$. Among the native Dutch, after adjustment for SES (now included as dichotomized variable), the increasing ORs with increasing Turkish or Moroccan density were considerably higher than the corresponding ORs in the former analysis (Table 2). This indicates that the adjustment with a dichtomized measure for neighborhood SES (in stead of categorization in quintiles, see Methods) is less adequate and this may also explain the absence of a within-group effect of ethnic density among the Turkish- and the Moroccan-Dutch in this analysis.

\subsection{Antidepressants: multivariable logistic regression}

Table 3 shows the results of the multivariable models on the dispensing of antidepressant medication. Remarkably, after adjustment for SES, no decreasing ORs with increasing own-group ethnic density were found among the Turkish-, Moroccan- (see also Supplementary Fig. 2), and Surinamese-Dutch. In contrast to the results for the dispensing of antipsychotics, even higher ORs were found compared to the corresponding ORs among the native Dutch. The ORs among these ethnic minorities became somewhat higher when adjusting for household composition. In contrast, among those of Antillean origin, a strong association was found with decreasing dispensing of antidepressant medication with increasing own-group ethnic density and highly significant terms for the $1^{\text {st }}$-order interaction ( $\mathrm{P}$ values $<0.001$ ), irrespective of what adjustment was applied.

\subsection{Antidepressants: multivariable logistic regression by age and gender}

Supplementary Table 3.1-3.4 show the results of the same analysis, but for separate age-gender strata. In general, the results followed the pattern found for the different ethnic groups as a whole (Table 3). There were a few exceptions. Among Surinamese females aged $<40$ years and among Moroccan females aged $\geq 40$ years, negative ('favourable') associations with higher own-group density were found.

\subsection{Antidepressants: multivariable logistic regression with multilevel modelling}

The results of this analysis confirmed the absence of a negative association between ethnic density and dispensing of antidepressants among Turkish-, Moroccan-, and Surinamese-Dutch persons. Among the Antillean-Dutch, a consistent decrease of the ORs with higher owngroup ethnic density and highly significant terms for the $1^{\text {st }}$-order interaction in the direction of an ethnic density effect were found $(\mathrm{P}<0.001)$.

\section{Discussion}

This study found strong and statistically significant associations between a higher own-group ethnic minority density and a lower prevalence of dispensing of antipsychotic medication. For those of 
Table 3

Use of antidepressants with increasing ethnic minority density of the neighborhood, by ethnic group.

\begin{tabular}{|c|c|c|c|c|c|c|}
\hline \multirow[t]{2}{*}{ ORs [95\%-CI], adjusted for: } & \multicolumn{3}{|c|}{ Within native Dutch } & \multicolumn{3}{|c|}{ Within ethnic minority associated with the density quintiles shown } \\
\hline & Age \& Gender & “ \& neighb. SES & “ \& household c. & Age \& Gender & “ \& neighb. SES & “ \& household c. \\
\hline \multicolumn{7}{|l|}{ Turkish density (\%) } \\
\hline 1. $<4.9$ & 1.00 & 1.00 & 1.00 & 1.00 & 1.00 & 1.00 \\
\hline 2. 4.9-9.4 & $1.14[1.12-1.17]$ & $1.05[1.02-1.07]$ & $1.05[1.03-1.07]$ & $1.15[1.08-1.23]$ & $1.09[1.02-1.16]$ & $1.13[1.05-1.20]$ \\
\hline 3. $9.4-14.0$ & $1,16[1.13-1.19]$ & $1.03[1.00-1.06]$ & $1.02[0.99-1.06]$ & $1.20[1.12-1.28]$ & $1.10[1.03-1.18]$ & $1.15[1.08-1.23]$ \\
\hline 4. $14.0-22.5$ & $1.18[1.14-1.23]$ & $1.04[1.00-1.09]$ & $1.03[0.99-1.08]$ & $1.19[1.12-1.28]$ & $1.09[1.01-1.16]$ & $1.14[1.07-1.22]$ \\
\hline $5 .>22.5$ & 1.27 [1.19-1.35] & $1.11[1.04-1.18]$ & $1.10[1.03-1.17]$ & $1.11[1.04-1.18]$ & $1.00[0.93-1.07]$ & $1.06[0.99-1.13]$ \\
\hline $\mathrm{P}$ value: within ${ }^{\mathrm{a}} /$ interaction $^{\mathrm{b}}$ & $<0.001^{\mathrm{a}}$ & $<0.001^{\mathrm{a}}$ & $<0.001^{\mathrm{a}}$ & $<0.001^{\mathrm{a}} / 0.0055^{\mathrm{b}}$ & $0.0012^{\mathrm{a}} / 0.0035^{\mathrm{b}}$ & $<0.001^{\mathrm{a}} /<0.001^{\mathrm{b}}$ \\
\hline \multicolumn{7}{|l|}{ Moroccan density (\%) } \\
\hline 1. $<5.7$ & 1.00 & 1.00 & 1.00 & 1.00 & 1.00 & 1.00 \\
\hline 2. $5.7-10.7$ & $1.08[1.06-1.11]$ & $0.98[0.96-1.00]$ & $0.97[0.95-1.00]$ & $1.09[1.02-1.16]$ & $1.02[0.95-1.09]$ & $1.05[0.98-1.12]$ \\
\hline 3. $10.7-15.8$ & $1.13[1.10-1.16]$ & $0.98[0.95-1.01]$ & $0.97[0.94-1.00]$ & $1.15[1.08-1.22]$ & $1.04[0.97-1.10]$ & $1.08[1.02-1.16]$ \\
\hline 4. $15.8-22.1$ & $1.06[1.03-1.10]$ & $0.91[0.88-0.95]$ & $0.90[0.86-0.93]$ & $1.12[1.05-1.20]$ & $1.00[0.94-1.07]$ & 1.07 [1.00-1.14] \\
\hline 5. $>22.1$ & $1.25[1.20-1.30]$ & $1.06[1.01-1.11]$ & $1.03[0.99-1.08]$ & $1.13[1.06-1.20]$ & $1.00[0.94-1.07]$ & $1.07[1.00-1.14]$ \\
\hline$P$ value: within $^{\mathrm{a}} /$ interaction $^{\mathrm{b}}$ & $<0.001$ & $<0.001$ & $<0.001$ & $\mathrm{P}<0.001 / 0.0027$ & $0.7204 / 0.0026$ & $0.1621 /<0.001$ \\
\hline \multicolumn{7}{|l|}{ Surinamese density (\%) } \\
\hline 1. $<5.5$ & 1.00 & 1.00 & 1.00 & 1.00 & 1.00 & 1.00 \\
\hline 2. $5.5-8,9$ & $1.10[1.08-1.12]$ & $0.98[0.96-1.00]$ & 1.01 [0.99-1.03] & 1.09 [1.01-1.17] & $1.00[0.93-1.08]$ & $1.03[0.95-1.11]$ \\
\hline 3. $8.9-11.8$ & $1.13[1.10-1.16]$ & $0.97[0.94-1.00]$ & $1.01[0.98-1.04]$ & $1.14[1.06-1.23]$ & $1.00[0.93-1.08]$ & $1.05[0.97-1.13]$ \\
\hline 4. $11.8-18.9$ & $1.18[1.15-1.22]$ & $1.05[1.02-1.09]$ & $1.10[1.06-1.13]$ & $1.34[1.24-1.45]$ & $1.21[1.12-1.31]$ & 1.29 [1.19-1.39] \\
\hline 5. $>18.9$ & $1.10[1.05-1.16]$ & $0.90[0.85-0.95]$ & $0.94[0.89-1.00]$ & $1.17[1.08-1.26]$ & $0.98[0.91-1.06]$ & $1.05[0.97-1.13]$ \\
\hline$P$ value: within ${ }^{\mathrm{a}} /$ interaction $^{\mathrm{b}}$ & $<0.001$ & $<0.001$ & $<0.001$ & $<0.001 / 0.0037$ & $<0.001 / 0.0036$ & $<0.001 /<0.001$ \\
\hline \multicolumn{7}{|l|}{ Antillean density (\%) } \\
\hline 1. $<1.1$ & 1.00 & 1.00 & 1.00 & 1.00 & 1.00 & 1.00 \\
\hline 2. $1.1-2.3$ & $1.10[1.08-1.12]$ & $1.04[1.02-1.06]$ & 1.06 [1.04-1.08] & $0.84[0.71-0.99]$ & $0.81[0.68-0.95]$ & $0.81[0.68-0.96]$ \\
\hline 3. $2.3-4.0$ & $1.15[1.12-1.18]$ & $1.04[1.01-1.07]$ & $1.05[1.02-1.08]$ & $0.77[0.65-0.91]$ & $0.70[0.59-0.83]$ & $0.70[0.59-0.83]$ \\
\hline 4. $4.0-5.9$ & $1.26[1.23-1.29]$ & $1.11[1.08-1.15]$ & $1.14[1.11-1.18]$ & $0.85[0.72-0.99]$ & $0.76[0.65-0.89]$ & $0.77[0.66-0.90]$ \\
\hline $5 .>5.9$ & 1.19 [1.14-1.24] & $1.03[0.99-1.08]$ & $1.06[1.02-1.11]$ & $0.70[0.59-0.83]$ & $0.62[0.52-0.74]$ & $0.62[0.52-0.74]$ \\
\hline P value: within ${ }^{\mathrm{a}} /$ interaction $^{\mathrm{b}}$ & $<0.001$ & $<0.001$ & $<0.001$ & $<0.001 /<0.001$ & $<0.001 /<0.001$ & $<0.001 /<0.001$ \\
\hline
\end{tabular}

a within: differences between ORs within a group $(\mathrm{df}=4)$.

b interaction: 1st-order interaction of $\{$ (ethnic minority vs. native Dutch) $\mathrm{x}$ ethnic density $\}(\mathrm{df}=4)$.

Moroccan and Turkish origin, this association became apparent after adjustment for neighborhood SES, and vanished after further adjustment for household composition. As the effect of higher ethnic density is operational in the opposite direction of the unfavourable effect of lower neighborhood SES, adjusting for neighborhood SES may be a requirement to make the favourable effect of ethnic density visible. For those of Surinamese and Antillean origin, these associations were present, irrespective of the type of adjustment applied. In general, the associations were also found in analyses stratified by age and gender. The importance of adjustment for SES among the Turkish- and Moroccan-Dutch was highlighted by multilevel analyses restricted to those without residential move in 2013. As the neighborhood SES was dichotomized for statistical-technical reasons in the multilevel analyses, and, thus, less adequate, the results of these analyses showed that the negative association with ethnic density among these minorities became only apparent after a direct comparison to the positive associations with ethnic minority density among the native Dutch. Since these analyses for the Surinamese and Antillean Dutch yielded similar results, we can be sure that ignoring the clustering of data within neighborhoods in the main analysis did not influence the results for these ethnic groups.

For the dispensing of antidepressants, a quite different picture was found. A negative association with the own-group ethnic density was observed consistently for the Antillean-Dutch only, whereas for the other ethnic groups even associations in the reverse direction were observed. Thus, this study confirms earlier findings concerning heterogeneity of ethnic density effects across different mental health outcomes and across different migrant groups, but also puts forward a number of important issues.

\subsection{Comparison with other studies}

Research on ethnic density is often motivated by referring to the vulnerable position of ethnic minorities and the associated high risk of psychiatric disorder (Shaw et al., 2012). A favourable effect of owngroup ethnic density is supposed to be a consequence of increased social support and a diminished influence of racism and discrimination. Few studies, however, investigated possible mechanisms underlying the ethnic density effect. Das-Munshi et al. (2010) reported an association between residence in areas with high own-group ethnic density and improved support and less reporting of discrimination, but none of these factors mediated the observed ethnic density effects on common mental disorders (Das-Munshi et al., 2010). Data from the same EMPIRIC study showed that living in areas with higher ethnic density was associated with lower scores on the Psychosis Screening Questionnaire (PSQ) (Das-Munshi et al., 2012). However, these associations were still present after adjusting the analysis for different indicators of social adversity and support, thus indicating that the effect of ethnic density may be operational independent of these potential mediators. The study of Becares et al. (2009) reported a tendency for a weaker association between perceived racism and the score on the PSQ with increasing ethnic density, but this finding failed to reach the level of statistical significance and, thus, remained inconclusive (Becares et al., 2009).

An important finding of our study is that the presence of an ethnic density effect for a certain mental health outcome does not necessarily imply an increased risk for that outcome in that particular migrant group, and, the other way round, a non-increased prevalence does not preclude the presence of an ethnic density effect. For those of Antillean origin, for example, ethnic density effects were found consistently, whereas the prevalence of antipsychotic dispensing was not increased and that of antidepressants was even significantly decreased, compared to the native Dutch (Termorshuizen et al., 2017). We found a pronounced effect of ethnic density on dispensing of antipsychotics among Moroccan males aged $<40$ years (Suppl. Table 2.1), in accordance with the high relative risks of psychosis found among Moroccan males of the second generation (Veling et al., 2006). However, we also found a clear 
and significant effect of ethnic density on dispensing of antipsychotics among Moroccan females aged $\geq 40$ years (Suppl. Table 2.4), whereas even a decreased risk of psychotic disorders was found among firstgeneration Moroccan females (Veling et al., 2006).

It is worthwhile to note that a lower rate may also indicate undertreatment and this does not preclude the favourable influence of increased social support and less racism and discrimination associated with higher ethnic density. However, significant ethnic density effects were also found for suicide as mental health outcome in combination with a substantially lower risk of suicide in non-Western migrant groups (Termorshuizen et al., 2015). The vulnerable position of ethnic minorities for certain mental health outcomes and the association with ethnic density may be distinct phenomena.

We found that the ethnic density effects on dispensed antipsychotics among the Turkish- and the Moroccan-Dutch disappeared after adjustment for household composition. It makes intuitive sense that being married or being part of a household with a married couple is associated with mental health. Notably, marital status is favourably associated with lower risk for psychosis and the available evidence suggests that causality operates in two directions: unmarried status is a result of psychopathology and unmarried status is a risk factor for psychopathology (Jablensky and Cole, 1997). However, this factor is not necessarily connected to the vulnerable ethnic minority position in terms of social adversity, racism, and discrimination. On the contrary, this finding rather suggests that observed ethnic density effects on neigborhood level may be a consequence of household- or individual-level characteristics. Other studies also questioned the presence of neigbhorhood-level influences, given proper adjustment for individual characteristics (Propper et al., 2005; Henderson et al., 2005). It is true, the study of Schofield et al. (2017) used a longitudinal design and showed that neighborhood-level exposure to own-group density established at age 15 predicted psychosis incidence long before the outcome (Schofield et al., 2017). Such a study may give substantial support for a causal relationship. However, household characteristics (eg, being member of a one-parent family) at the age of 15 and/or at the time of diagnosis were not taken into account.

Among those of Surinamese or Antillean origin, the association between own-group ethnic density and risk for dispensing of antipsychotics was present, even after adjustment for household characteristics. This is in accordance with another study in the Netherlands, in which the most pronounced association between ethnic density and risk of non-affective psychosis was found for the Surinamese- and Antillean-Dutch (Termorshuizen et al., 2014). Among these ethnic minorities, a higher own-group ethnic density was associated with a higher rate of single-parent families (Table 1A). Living in a household with a single parent was associated with a higher use of antipsychotics (results not shown), and, thus, adjustment for household composition may be supposed to have a different effect on the estimates than adjustment for household composition among the Turkish- and MoroccanDutch. This indicates that the heterogeneity concerning ethnic density effects may be complicated by heterogenity concerning underlying mechanisms and correlates.

\subsection{Strengths and limitations}

Our population-based study included a large sample of more than one million native Dutch individuals and more than 400,000 first- and second-generation immigrants. It used administrative data of high quality, that was fully independent of willingness or ability to participate in surveys and that was not influenced by any recall bias. The use of data from Statistics Netherlands guaranteed a correct identification of ethnic origin. This study contributes to the literature on density effects as it combines data on psychosis and data on more common mental disorders within the same population and using identical analytic methods. The minority ethnic density effect was also evaluated within the population of native Dutch persons. This was done to illustrate the important influence of SES on use of psychomedication. Among those of the majority population, the effect of low SES and the effect of higher minority ethnic density (that is, lower native Dutch density) are operational in the same direction. The effect of ethnic density was not analyzed as the relative risk of a mental health outcome among ethnic minorities compared to natives in high density areas vs. this relative risk in low-ethnic density areas. Such an analysis may lead to spurious ethnic density effects, due to a high prevalence of disorder among natives in high minority-density (and low SES) areas, and not necessarily by a low prevalence among ethnic minorities in these areas (Termorshuizen et al., 2014). We decided to report the broad outline of our analysis in accordance with our original research proposal, to avoid the pitfall of focusing on findings and details that agree with certain lines of reasoning and nice hypotheses that were conceived and formulated after scrutinizing the data. A number of limitations, however, has to be noted.

At first, there are important limitations to the database concerning the availability of the data on medication in crude format and only per calander year, the restricted number of covariables, the definition of ethnicity on the basis of country of origin and not as self-identified ethnicity, and the measurement of SES on neighborhood level. These limitations were discussed in depth before in our earlier study of the same database (Termorshuizen et al., 2017). Secondly, there are important limitations related to the present analysis of ethnic density effects. Our analysis was cross-sectional in nature, and this precludes the establishment of cause-effect relationships. Furthermore, lower rates of medication dispensing in high ethnic density areas may also be a consequence of undertreatment. Ethnic minorities living in these neighborhoods may be more oriented towards their culture of origin and less inclined to make use of Western medicine for mental disorders. This may be applicable especially to less severe disorders, that may more easily escape the attention of the GP and/or mental health care. In the present study, however, a higher ethnic density was often associated with a higher, not lower dispensing of antidepressants among ethnic minorities. This does not support undertreatment as explanation for observed ethnic density effects on dispensing of antipsychotic medication. Still, as dispensed medication as outcome necessarily implies an 'equation with two unknown variables' (ie, one related to the presence of the disorder, the other with treatment characteristics such as access to mental health care and treatment compliance), our primary and modest aim was to explore whether results from population-based administrative databases on medication dispensing and effects of ethnic density confirm earlier epidemiological findings derived from smaller samples with more detailed information on timing and diagnosis. Further studies should examine whether a change in exposure to owngroup ethnic density is associated with a subsequent change in use of certain classes of psychomedication. As the combination of the number of ethnic minorities, the many classes of psychomedication, subgroups, and possible adjustment strategies results in huge amounts of hardly manageable statistical output, it is adviceable to restrict future analyses to a part of the data and to start from one clear research question. One important topic may concern the possible differences between first- and second generation immigrants in the use of psychomedication and effects of ethnic density (Schofield et al., 2018).

\section{Conclusion}

The present analysis confirms earlier findings on the presence of ethnic density effects on mental health outcomes among ethnic minorities, but also on the heterogeneity of such effects across particular outcomes, ethnic minority groups, associated correlates and underlying mechanisms. The results of the present study also indicate that consistent and significant effects of neighborhood-level characteristics may still be due to individual- or household-level characteristics, that are not necessarily connected with the vulnerable position of ethnic minority groups. The unexplained issues concerning the presence and possible 
mechanisms of ethnic density effects warrant further investigations with different outcomes, but make direct translation into public health interventions probably a little premature.

\section{Conflicts of interest}

On behalf of all authors, the corresponding author states that there is no conflict of interest.

\section{Acknowledgements}

The authors thank Statistics Netherlands (Centraal Bureau voor de Statistiek, CBS) and Health Care Institute Netherlands (Zorginstituut Nederland, ZiN) for kindly providing the data necessary for the present analysis. The authors thank the Netherlands Organization for Health Research and Development for financial support of this project (grant number 836022003).

\section{Appendix A. Supplementary data}

Supplementary data related to this article can be found at http://dx. doi.org/10.1016/j.socscimed.2018.06.005.

\section{References}

Becares, L., Nazroo, J., Stafford, M., 2009. The buffering effects of ethnic density on experienced racism and health. Health Place 15 (3), 670-678.

Becares, L., Nazroo, J., Jackson, J., 2014. Ethnic density and depressive symptoms among African Americans: threshold and differential effects across social and demographic subgroups. Am. J. Publ. Health 104 (12), 2334-2341.

Becares, L., Dewey, M.E., Das-Munshi, J., 2017. Ethnic density effects for adult mental health: systematic review and meta-analysis of international studies. Psychol. Med. $1-19$.

Bhugra, D., Hilwig, M., Hossein, B., Marceau, H., Neehall, J., Leff, J., et al., 1996. Firstcontact incidence rates of schizophrenia in Trinidad and one-year follow-up. Br. J. Psychiatry 169 (5), 587-592.

Bosqui, T.J., Hoy, K., Shannon, C., 2014. A systematic review and meta-analysis of the ethnic density effect in psychotic disorders. Soc. Psychiatr. Psychiatr. Epidemiol. 49 (4), 519-529.

Bourque, F., van der Ven, E., Malla, A., 2011. A meta-analysis of the risk for psychotic disorders among first- and second-generation immigrants. Psychol. Med. 41 (5), 897-910.

Cantor-Graae, E., Selten, J.P., 2005. Schizophrenia and migration: a meta-analysis and review. Am. J. Psychiatr. 162 (1), 12-24.

Das-Munshi, J., Becares, L., Dewey, M.E., Stansfeld, S.A., Prince, M.J., 2010. Understanding the effect of ethnic density on mental health: multi-level investigation of survey data from England. BMJ 341 c5367.

Das-Munshi, J., Becares, L., Boydell, J.E., Dewey, M.E., Morgan, C., Stansfeld, S.A., et al., 2012. Ethnic density as a buffer for psychotic experiences: findings from a national survey (EMPIRIC). Br. J. Psychiatry 201 (4), 282-290.

Denton, E.G., Shaffer, J.A., Alcantara, C., Clemow, L., Brondolo, E., 2015. Hispanic residential ethnic density and depression in post-acute coronary syndrome patients: Rethinking the role of social support. Int. J. Soc. Psychiatr. 61 (3), 225-235.

Fearon, P., Morgan, C., 2006. Environmental factors in schizophrenia: the role of migrant studies. Schizophr. Bull. 32 (3), 405-408.

Halpern, D., Nazroo, J., 2000. The ethnic density effect: results from a national community survey of England and Wales. Int. J. Soc. Psychiatr. 46 (1), 34-46.

Henderson, C., Diez Roux, A.V., Jacobs Jr., D.R., Kiefe, C.I., West, D., Williams, D.R. 2005. Neighbourhood characteristics, individual level socioeconomic factors, an depressive symptoms in young adults: the CARDIA study. J. Epidemiol. Community Health 59 (4), 322-328.

Hooghiemstra TFM. Privacy bij wetenschappelijk onderzoek en statistiek. Kader voor een gedragscode. In: Persoonsgegevens CB, editor. Den Haag, 2002.

Hull, S.A., Cornwell, J., Harvey, C., Eldridge, S., Bare, P.O., 2001. Prescribing rates for psychotropic medication amongst east London general practices: low rates where Asian populations are greatest. Fam. Pract. 18 (2), 167-173.

Jablensky, A., Cole, S.W., 1997. Is the earlier age at onset of schizophrenia in males a confounded finding? Results from a cross-cultural investigation. Br. J. Psychiatry
$170,234-240$

Mair, C., Diez Roux, A.V., Osypuk, T.L., Rapp, S.R., Seeman, T., Watson, K.E., 2010. Is neighborhood racial/ethnic composition associated with depressive symptoms? The multi-ethnic study of atherosclerosis. Soc. Sci. Med. 71 (3), 541-550.

Mindlis, I., Boffetta, P., 2017. Mood disorders in first- and second-generation immigrants: systematic review and meta-analysis. Br. J. Psychiatry 210 (3), 182-189.

Morrison, J., Anderson, M.J., Sutton, M., Munoz-Arroyo, R., McDonald, S., Maxwell, M., et al., 2009. Factors influencing variation in prescribing of antidepressants by general practices in Scotland. Br. J. Gen. Pract. 59 (559), e25-31.

Propper, C., Jones, K., Bolster, A., Burgess, S., Johnston, R., Sarker, R., 2005. Local neighbourhood and mental health: evidence from the UK. Soc. Sci. Med. 61 (10), 2065-2083.

Rabe-Hesketh, S.S., 2005. A.. Multilevel and Longitudinal Modeling Using STATA, first ed. STATA Press, Texas.

Schofield, P., Das-Munshi, J., Mathur, R., Congdon, P., Hull, S., 2016a. Does depression diagnosis and antidepressant prescribing vary by location? Analysis of ethnic density associations using a large primary-care dataset. Psychol. Med. 46 (6), 1321-1329.

Schofield, P., Das-Munshi, J., Becares, L., Morgan, C., Bhavsar, V., Hotopf, M., et al., 2016b. Minority status and mental distress: a comparison of group density effects. Psychol. Med. 46 (14), 3051-3059.

Schofield, P., Thygesen, M., Das-Munshi, J., Becares, L., Cantor-Graae, E., Pedersen, C., et al., 2017 Dec. Ethnic density, urbanicity and psychosis risk for migrant groups - a population cohort study. Schizophr. Res. 190, 82-87. http://dx.doi.org/10.1016/j. schres.2017.03.032.

Schofield, P., Thygesen, M., Das-Munshi, J., Becares, L., Cantor-Graae, E., Agerbo, E., et al., 2018 May. Neighbourhood ethnic density and psychosis - is there a difference according to generation? Schizophr. Res. 195, 501-505. http://dx.doi.org/10.1016/j. schres.2017.09.029.

Schrier, A.C., Peen, J., de Wit, M.A., van Ameijden, E.J., Erdem, O., Verhoeff, A.P., et al., 2014. Ethnic density is not associated with psychological distress in Turkish-Dutch, Moroccan-Dutch and Surinamese-Dutch ethnic minorities in The Netherlands. Soc. Psychiatr. Psychiatr. Epidemiol. 49 (10), 1557-1567.

Selten, J.P., Veen, N., Feller, W., Blom, J.D., Schols, D., Camoenie, W., et al., 2001. Incidence of psychotic disorders in immigrant groups to The Netherlands. Br. J. Psychiatry $178,367-372$.

Selten, J.P., Laan, W., Veen, N.D., Blom, J.D., Veling, W., Hoek, H.W., 2010. Incidence of schizophrenia among Moroccan immigrants to The Netherlands. Schizophr. Res. 124 (1-3), 240-241.

Shaw, R.J., Atkin, K., Becares, L., Albor, C.B., Stafford, M., Kiernan, K.E., et al., 2012. Impact of ethnic density on adult mental disorders: narrative review. Br. J. Psychiatry 201 (1), 11-19.

Shields, M.A., Wailoo, A., 2002. Exploring the determinants of unhappiness for ethnic minority men in Britain. Scot. J. Polit. Econ. 49 (4), 445-466.

Tarricone, I., Stivanello, E., Poggi, F., Castorini, V., Marseglia, M.V., Fantini, M.P., et al., 2012. Ethnic variation in the prevalence of depression and anxiety in primary care: a systematic review and meta-analysis. Psychiatr. Res. 195 (3), 91-106.

Termorshuizen, F., Smeets, H.M., Braam, A.W., Veling, W., 2014. Neighborhood ethnic density and psychotic disorders among ethnic minority groups in Utrecht City. Soc. Psychiatr. Psychiatr. Epidemiol. 49 (7), 1093-1102.

Termorshuizen, F., Braam, A.W., van Ameijden, E.J., 2015. Neighborhood ethnic density and suicide risk among different migrant groups in the four big cities in The Netherlands. Soc. Psychiatr. Psychiatr. Epidemiol. 50 (6), 951-962.

Termorshuizen, F., Selten, J.P., Heerdink, E.R., 2017. Dispensing of psychotropic medication among 400,000 immigrants in The Netherlands. Soc. Psychiatr. Psychiatr. Epidemiol. 52 (8), 963-977.

Veling, W., Selten, J.P., Veen, N., Laan, W., Blom, J.D., Hoek, H.W., 2006. Incidence of schizophrenia among ethnic minorities in The Netherlands: a four-year first-contact study. Schizophr. Res. 86 (1-3), 189-193.

Veling, W., Susser, E., van Os, J., Mackenbach, J.P., Selten, J.P., Hoek, H.W., 2008. Ethnic density of neighborhoods and incidence of psychotic disorders among immigrants. Am. J. Psychiatr. 165 (1), 66-73.

van der Ven, E., Dalman, C., Wicks, S., Allebeck, P., Magnusson, C., van Os, J., et al., 2015. Testing Odegaard's selective migration hypothesis: a longitudinal cohort study of risk factors for non-affective psychotic disorders among prospective emigrants. Psychol. Med. 45 (4), 727-734.

Walters, P., Ashworth, M., Tylee, A., 2008. Ethnic density, physical illness, social deprivation and antidepressant prescribing in primary care: ecological study. Br. J. Psychiatry 193 (3), 235-239.

Yuan, A.S.V., 2008. Racial composition of neighborhood and emotional well-being. Socio. Spectr. 28 (1), 105-129.

Zandi, T., Havenaar, J.M., Smits, M., Limburg-Okken, A.G., van Es, H., Cahn, W., et al., 2010. First contact incidence of psychotic disorders among native Dutch and Moroccan immigrants in The Netherlands: influence of diagnostic bias. Schizophr. Res. 119 (1-3), 27-33. 